\title{
HSULF-1 inhibits ERK and AKT signaling and decreases cell viability in vitro in human lung epithelial cells
}

Huiying Zhang ${ }^{1,2}$, Donna R Newman ${ }^{1}$ and Philip L Sannes ${ }^{1 *}$

\begin{abstract}
Background: Heparan sulfate proteoglycans (HSPGs) modulate the binding and activation of signaling pathways of specific growth factors, such as fibroblast growth factor-2 (FGF-2). Human endosulfatase 1 (HSULF-1) is an enzyme that selectively removes 6-O sulfate groups from HS side chains and alter their level and pattern of sulfation and thus biological activity. It is known that HSULF-1 is expressed at low levels in some cancer cell lines and its enhanced expression can inhibit cancer cell growth or induce apoptosis, but the mechanism(s) involved has not been identified.
\end{abstract}

Methods: HSULF-1 mRNA expression was assessed in five normal cells (primary human lung alveolar type 2 (hAT2) cells, adult lung fibroblasts (16Lu), fetal lung fibroblasts (HFL), human bronchial epithelial cells (HBE), and primary human lung fibroblasts (HLF)) and five lung cancer cell lines (A549, H292, H1975, H661, and H1703) using quantitative real time polymerase chain reaction (qRT-PCR). H292 and hAT2 cells over-expressing HSULF-1 were analyzed for cell viability, apoptosis, and ERK/Akt signaling, by MTT (3-(4,5-Dimethylthiazol-2-yl)-2,5-

diphenyltetrazolium bromide) assay, TUNEL (Terminal deoxynucleotidyl transferase dUTP nick end labeling) assay, and Western Blot, respectively. Apoptosis pathway activation was confirmed by PCR array in hAT2, H292, and A549 cells.

Results: HSULF-1 was expressed at a significantly lower level in epithelial cancer cell lines compared to normal cells. Infection with recombinant adenovirus for HSULF-1 over-expression resulted in decreased cell viability in H292 cells, but not in normal hAT2 cells. HSULF-1 over-expression induced apoptosis in H292 cells, but not in hAT2 cells. In addition, apoptosis pathways were activated in both $\mathrm{H} 292$ and A549 cells, but not in hAT2 cells. HSULF-1 over-expression reduced ERK and Akt signaling activation in $\mathrm{H} 292$ cells, which further demonstrated its inhibitory effects on signaling related to proliferation.

Conclusions: These results indicate that HSULF-1 is expressed at lower levels in H292 lung cancer cells than in normal human alveolar cells and that its over-expression reduced cell viability in $\mathrm{H} 292$ cells by inducing apoptotic pathways, at least in part by inhibiting ERK/Akt signaling. We hypothesize that HSULF-1 plays important roles in cancer cells and functions to modify cell signaling, inhibit cancer proliferation, and promote cancer cell death.

Keywords: Human endosulfatase 1, Heparan sulfate proteoglycans

\footnotetext{
* Correspondence: philip_sannes@ncsu.edu

'Department of Molecular Biomedical Sciences, Center for Comparative Molecular Translational Research, College of Veterinary Medicine, North Carolina State University, Raleigh, NC 27606, USA

Full list of author information is available at the end of the article
} 


\section{Background}

Heparan sulfate (HS) proteoglycans are major components of extracellular matrix (ECM) and cell surfaces. They function as dynamic interfaces between cells and their external environment. They help cells affix to and maintain the extracellular scaffolding of the ECM as well as directly internalize lipid factors. Their shed ectodomain fragments can even neutralize injurious agents [1-4]. Importantly, they regulate essential cell signaling pathways which influence proliferation, differentiation, migration, and survival [3,5]. HS side chains are covalently linked to core proteins to form proteoglycans, such as syndecans or glypicans, which associate with or integrate into the lipid bi-layers of cells. HS side chains are also key structural features which facilitate ligand binding and receptor activation for an important group of signaling molecules which includes fibroblast growth factors (FGFs), wingless signaling glycoproteins (Wnts), Sonic hedgehog (Shh), hepatocytes growth factor (HGF), vascular endothelial growth factor (VEGF), and a newly defined tumor necrosis family member, a proliferationinducing ligand (APRIL) [6-11]. For example, the loss of responsiveness to FGF by cells lacking endogenous heparan sulfate can be restored by the addition of exogenous soluble heparin [12]. Importantly, there is strong evidence that the nature of the sulfate bonds and the pattern distribution of sulfation are critical factors influencing signaling pathways $[13,14]$. FGF-2 signaling, for instance, requires the $\mathrm{N}$ - and 2-O-sulfate groups of heparan sulfate for binding to FGF-2 ligands and the presence of 6-O-sulfate groups for the activation of FGF receptor-1 (FGFR-1). Accordingly, 6-O-desulfated heparin, which binds to FGF-2 ligands but fails to bind to the FGFR, can decrease the FGF-2-induced proliferation of CHO677 cells [15].

Human endosulfatase-1 (HSULF-1) is the enzyme that specifically removes 6-O sulfate groups from $\mathrm{HS}$ side chains, thus modifying the pattern of sulfation and potentially changing its biological specificity. Although its quail analog QSULF-1 was found to be a secreted protein, HSULF-1 has been shown to be both secreted and localized on external cell surfaces as well as electrostatically attached to cell membranes $[13,16,17]$. Recently, the role HSULF-1 plays in cancer cell proliferation and embryonic development has been studied by several groups. The expression of HSULF-1 was found to be down-regulated in ovarian, breast, and hepatocellular cancers compared with normal epithelium $[10,18]$, and its over-expression reduced tumor growth in several cancer types $[19,20]$. These collective observations support the notion that HSULF-1 plays an important role in the biology of some cancer cells. However, few studies have examined HSULF-1 activity in normal and cancer cells of the lung, the regulation of its expression, and its capacity to modulate lung cell proliferation and relevant signaling via hydrolyzation of $6-\mathrm{O}$ sulfate groups. Accordingly, the aim of this study was to examine the expression of HSULF-1 and the effects of its overexpression in transformed human epithelial cells of pulmonary origin as compared with normal human alveolar type 2 cells.

\section{Materials and methods \\ Cell preparation}

H292, A549, HFL-1, and 16Lu cells were obtained from the American Type Culture Collection (ATCC) (Manassas, VA) and cultured in RPMI1640 (Roswell Park Memorial Institute 1640), F12K, and EMEM (Eagle's minimal essential medium) media, respectively, with $10 \%$ FBS and antibiotics. Human AT2 cells and HLF cells were isolated from organ donor lungs obtained by the University of North Carolina Cystic Fibrosis/ Pulmonary Research and Treatment Center Tissue Procurement and Cell Culture Core (Chapel Hill, NC). Isolated hAT2 cells were maintained in low-glucose DMEM (Dulbecco's modified Eagle medium) medium supplemented with 10\% FBS and Antibiotic-Antimycotic solution containing penicillin, streptomycin, and amphotericin B (Mediatech, Manassas, VA). Isolated HLF cells were maintained in high-glucose DMEM medium with 10\% FBS and antibiotics. H1975, H661, and H1703 cells were purchased from Duke University's Cell Culture Facility (Durham, NC) and maintained in RPMI medium with 10\% FBS and antibiotics. HBE cells were gifts from Dr. Kenneth Adler and was maintained in Ham's F-12/ DMEM medium supplemented with $5 \mathrm{mg} / \mathrm{ml}$ insulin, 10 $\mathrm{ng} / \mathrm{ml}$ epidermal growth factor, $0.1 \mathrm{mM}$ dexamethasone, $5 \mathrm{mg} / \mathrm{ml}$ transferring, $20 \mathrm{ng} / \mathrm{ml}$ cholera toxin, and antibiotics. The use of human cells was in compliance with the Helsinki Declaration, and approved by the North Carolina State University Institutional Review Board for the Protection of Human Subjects in Research.

\section{hAT2 and HLF cell isolation}

Cells were isolated according to a scaled-up, modified version of the original Dobbs [21] procedure. In brief, an entire lobe from a donor cadaver lung was excised, cannulated, inflated to full capacity with Solution I, a PBS (phosphate buffered saline)-based solution lacking calcium and magnesium but containing EGTA, and lavaged and drained multiple times to remove macrophages, air and mucus. Divalent cations were restored by inflating with Solution II, a PBS-based solution containing magnesium and calcium. The lobe was inflated to capacity with elastase (Worthington Biochemicals, Lakewood, NJ) dissolved in Solution II (13 units $/ \mathrm{ml}$ ) and incubated at $37^{\circ} \mathrm{C}$ for up to forty minutes. Peripheral pieces were excised from the digested lobe and obvious bronchiolar 
tissue was removed and discarded. Tissue pieces were then minced into cubic millimeter size, using triple scissors, in Solution II containing DNase (Worthington). The minced tissue was transferred to a flask on ice and $5 \mathrm{ml}$ of FBS was added to each $100 \mathrm{ml}$ of suspension to neutralize the elastase. The suspension was shaken vigorously side-to-side in a $37^{\circ} \mathrm{C}$ water bath for 3 minutes to mechanically release the hAT2 and HLF cells from the tissue. The suspension was then filtered through a single layer of moistened cheesecloth several times until large pieces of undigested tissue were removed, then through two layers of cheesecloth twice and three layers once. The suspension was passed through $165 \mu$ m nylon mesh and finally through $42 \mu \mathrm{m}$ nylon mesh. The filtrate was centrifuged at $1000 \mathrm{rpm}$ (300 g) for 10 minutes at $4^{\circ} \mathrm{C}$, and each cell pellet was re-suspended in $5 \mathrm{ml}$ DMEM (without FBS) and pooled. A $100 \mu \mathrm{l}$ aliquot of the cells was diluted 1:10 in a Trypan Blue solution and counted using a hemacytometer. Cells were resuspended in sufficient DMEM so that around 20 million viable cells could be seeded on each of 40 Petri dishes coated with human IgG (Sigma, St. Louis, MO). Dishes of cells were incubated at $37^{\circ} \mathrm{C}$ for 1 hour to allow macrophages and white blood cells, as well as many fibroblasts, to adhere. Non-attached hAT2 cells were recovered by gently rocking each dish several times, transferred to $50 \mathrm{ml}$ tubes, and centrifuged. Each hAT2 cell pellet was re-suspended in $5 \mathrm{ml}$ DMEM and all cells were pooled in a single $50 \mathrm{ml}$ tube. To further reduce fibroblast contamination, a mouse monoclonal antiCD90/anti-fibroblast antibody, clone AS02 (EMD Biosciences, Inc., La Jolla, CA), was added to the cells for a 10 minute incubation at $4^{\circ} \mathrm{C}$ with gentle inversion. Excess antibody was removed by increasing the volume to $50 \mathrm{ml}$ with DMEM/0.1\% BSA and by pelleting the cells. The re-suspended cells (in $20 \mathrm{ml}$ DMEM/0.1\% BSA) were then incubated with pan-mouse-IgG Dynabeads for 30 minutes at $4^{\circ} \mathrm{C}$ with gentle inversion. The cell suspension was brought to $45 \mathrm{ml}$ with DMEM/0.1\% BSA and divided into three $15 \mathrm{ml}$ tubes. Tubes were placed into a magnetic holder and the Dynabead-labeled fibroblasts were immobilized along the tube sides. The nonselected hAT2 cells were pooled in a $50 \mathrm{ml}$ tube, counted, and plated in DMEM/10\% FBS on rat-tail collagen-coated tissue culture dishes. After a medium change the next day, cells were cultured for 48 hours before further treatment. To obtain HLF cells, a portion of the mixed cell population which was not ASO2 depleted was placed on tissue culture dishes and cultured in complete medium until fibroblasts began to proliferate. These HLF cells were lightly trypsinized, transferred to flasks for amplification, and cryopreserved at passage 3. Cell culture and treatment, H292, A549, H1975, H661, H1703, HFL-1, 16Lu, HBE, HLF, and hAT2 cells were cultured for
48 hours and harvested for RNA analysis to measure the basal expression of HSULF-1. H292 and hAT2 cells were then cultured to $50 \%$ confluence and transduced with HSULF-1 adenovirus at 2, 5, 10, 20, 50, and 100 multiplicities of infection (MOI). After 24 or 48 hours, enzymatic conversion of formazan, an indirect measure of cell proliferation/viability, was measured by MTT assay. TUNEL assay was also utilized to confirm the cell death in transduced H292 cells over-expressing HSULF-1. In addition, H292, A549, and hAT2 cells, transduced at 10 MOI to over-express HSULF-1, were harvested for RNA and apoptosis pathway activation was analyzed by PCR array. Finally, selected signaling events influenced by over-expression of HSULF-1 were analyzed in H292 cells with or without $25 \mu \mathrm{g} / \mathrm{ml}$ heparin (Bovine lung, sodium salt, EMD Biosciences).

\section{Preparation of HSULF-1 adenovirus}

Over-expression of HSULF-1 in epithelial cells was accomplished by adenoviral delivery of the human SULF-1 gene driven by a CMV promoter. An Ultimate ORF (open reading frame) clone ( $\mathrm{IOH} 38422$ ) in the $\mathrm{pENTR221}$ vector (Invitrogen, Carlsbad, CA) was used to introduce the protein coding sequence of HSULF-1 into the pAd/ CMV/V5-DEST vector (Invitrogen) by an LR Clonase II transfer and ligation reaction. The recombinant plasmid was transformed into TOP10 E. coli hosts and successful transformants were selected on Ampicillin plates. The HSULF-1 coding DNA was completely sequenced by primer walking to confirm $100 \%$ fidelity and a perfect clone was amplified and used to transfect 293A cells to produce adenovirus. Amplified adenoviruses were then titered by the Hexon antibody/DAB method and used to infect experimental hAT2 and H292 cells for transient over-expression of HSULF-1.

\section{MTT assay}

A measure of cell proliferation/viability was obtained by a colorimetric assay which utilized the capacity of live cells to change 3-(4,5-dimethylthiazol-2-yl)-2, 5diphenyltetrazolium bromide (MTT) from yellow to a purple precipitate which could be dissolved in DMSO. Twenty-four, 48, or 72 hours after adenovirus infection of H292 and hAT2 cells, culture medium was discarded and the MTT solution (Sigma) was added to a final concentration of $1 \mathrm{mg} / \mathrm{ml}$. After 3 hours of incubation at $37^{\circ} \mathrm{C}$, the solution was removed and the formazan precipitate was dissolved in DMSO. Optical densities (OD) were measured at $570 \mathrm{~nm}$ using a microplate ELISA reader. Data was expressed as a percentage of untreated control cells and analyzed by ANOVA followed by Student's $t$-test. 


\section{TUNEL assay}

Apoptosis was determined by TUNEL (Terminal deoxynucleotidyl transferase dUTP nick and end labeling) assay which detects the DNA fragmentation produced in apoptotic cells. Cells over-expressing HSULF-1 or lacZ (controls) were cultured for 72 hours, trypsinized, culture, washed, and re-suspended in $500 \mu \mathrm{l} \mathrm{PBS}$. Each cell suspension was delivered into $5 \mathrm{ml}$ of $1 \%$ paraformaldehyde. After incubation on ice for 15 minutes, cells were pelleted and supernatant discarded; cells were then washed twice in $5 \mathrm{ml}$ of PBS and finally re-suspended in $500 \mu \mathrm{l} \mathrm{PBS}$. This cell suspension was added to $5 \mathrm{ml}$ of ice cold $70 \%$ ethanol, incubated on ice for 30 minutes, and pelleted again. Apoptosis was analyzed by a TUNEL kit (Invitrogen) which uses an anti-BrdU mouse antibody and Alexa Fluor 488 conjugate. Cells undergoing apoptosis exhibited a bright green nuclear fluorescence at excitation/emission wavelengths of 495/519 nm. Total cell nuclei were stained with DAPI (blue) and detected at excitation/emission wavelengths of 358/461 nm. Photomicrographs were taken of random fields with a Meiji $\mathrm{MT} 6300 \mathrm{H}$ fluorescence microscope at 20X magnification with an Infinity 3 camera; DAPI and BrdU pictures were merged using Image J. A minimum of 3 fields was randomly selected and total cells were counted in each field to achieve a minimum number of 150 total. Apoptotic ratios as apoptotic cells/total cells are expressed as Mean \pm standard error (SD) from different fields.

\section{Reverse transcription and quantitative real-time PCR}

Cells were cultured as above for 48 hours and total RNA was isolated using the RNeasy Plus Mini Kit (Qiagen, Valencia, CA) according to manufacturer's protocol. Four micrograms of RNA of each sample were reversetranscribed utilizing the High-Capacity Archive Kit (Applied Biosystems, Foster City, CA). cDNAs were diluted to a final concentration of $10 \mathrm{ng} / \mathrm{ml}$ and $10 \mu \mathrm{l}$ of each diluted sample (equivalent to $100 \mathrm{ng}$ of RNA) were PCR-amplified in triplicate using Taqman primers and probes (Hs00392839_m1) (Applied Biosystems) on an iCycler (Bio-Rad, Hercules, CA). Data analysis was performed using the delta-delta CT method to compare the relative expression of HSULF-1 normalized to GAPDH in different cell types; values and standard errors were graphed in Excel.

\section{PCR array analysis of apoptosis signaling pathways}

hAT2, A549, and H292 cells were infected with lacZ or HSULF-1 adenovirus at 10 MOI for 48 hours. Cells were harvested and total RNA was isolated and purified by RNeasy Plus Mini Kit (Qiagen). Concentrations were measured spectrophotometrically at $260 \mathrm{~nm}$ and $1 \mu \mathrm{g}$ of total mRNA was used as template for cDNA synthesis utilizing the High Capacity Archive Kit (Applied
Biosystems). Produced cDNA was added to SybrGreen PCR master mix (SABiosciences, Frederick, MD) and aliquotted into each well of the ready-to-use PCR array PAHS-012 (Human apoptosis array, SABiosciences). Realtime PCR cycling was performed according to the protocol and data were analyzed using on-line programs from SABiosciences. The 84 apoptosis-related genes analyzed included tumor necrosis factor (TNF) ligand and receptor family, B-cell lymphoma 2 (BCL2) families, Caspases, Inhibitors of apoptosis (IAP), caspase recruitment domain family, death domain, death effector domain, and p53 family members.

\section{Preparation of cell lysates}

Cells, cultured in $100 \mathrm{~mm}$ dishes, were rinsed with PBS. RIPA buffer $(150 \mu \mathrm{l})$, containing PhosStop and Complete EDTA-free Protease inhibitors (Roche, Indianapolis, IN), was added to dishes. Cells were scraped and collected in microcentrifuge tubes and sonicated three times. Samples were then shaken on ice for at least 30 minutes and centrifuged at $14,000 \mathrm{rpm}$ for 30 minutes at $4^{\circ} \mathrm{C}$. Supernatants were transferred to fresh microcentrifuge tubes and total proteins in each sample were quantitated by Pierce $660 \mathrm{~nm}$ Protein Assay Kit (Pierce Biotechnology, Rockford, IL). The lysates were stored at $-80^{\circ} \mathrm{C}$.

\section{Western analysis}

Equal amounts of proteins were subjected to electrophoretic separation in MOPS running buffer at $200 \mathrm{~V}$ for 60 minutes on NuPage 4-12\% Bis-Tris gels using the Novex X-Cell II system (Invitrogen). Proteins were transferred to nitrocellulose membranes and blocked with TBST $/ 5 \%$ milk for 1 hour. Blocked membranes were incubated in Tris Buffered Saline containing 0.1\% Tween 20 and 5\% BSA (TBS/T/BSA) with primary antibodies to HSULF-1 (Abcam, Cambridge, MA), p-ERK, ERK, p-Akt, Akt, and GAPDH (Cell Signaling Technology, Danvers, MA) overnight at $4^{\circ} \mathrm{C}$ with agitation. After washing in TBS/T, blots were incubated in $\mathrm{TBS} / \mathrm{T}$ with $5 \%$ milk (TBS/T/milk) containing secondary antibodies conjugated to horseradish peroxidase (Cell Signaling Technology) for 2 hours with agitation. Bands on the membrane were detected by chemiluminescence using SuperSignal West Pico or Dura substrate (Pierce) and visualized by autoradiography. Integrated optical densities measured by ImageJ were exported to Microsoft Excel for analysis.

\section{Statistical analysis}

Certain RT-PCR data were log transformed to obtain normally distributed variables. Values were expressed as mean \pm SD and statistical significances were established by one or two tailed $t$-test and ANCOVA (analysis of covariance). A level of $p<0.05$ was considered significant. 


\section{Results}

HSULF-1 basal expression is lower in lung cancer cells than in normal lung cells

To evaluate the expression of HSULF-1 in cells of pulmonary origin, five normal lung cells (fibroblasts (16Lu), fetal lung fibroblasts (HFL), primary lung fibroblasts (HLF), primary alveolar type 2 (hAT2) cells, and bronchial epithelial cells (HBE)) and five lung epithelial cancer cell lines (A549, H292, H1975, H661, and H1703) were cultured and mRNAs were analyzed. HSULF-1 was expressed at a significantly higher level in normal lung cells (hAT2 (61-fold), HFL-1 (94-fold), 16Lu (133- fold), HBE (74-fold), and HLF (362-fold) compared to cancer cells (A549 as control, H292 (6-fold), H1975 (10-fold), H661 (2-fold), and H1703 (12-fold)) (Figure 1). This suggests that the expression of HSULF-1 may be constitutively lower in lung cancer cells compared to normal cell lines or primary cells.

\section{Over-expression of HSULF-1 decreased cell density in} H292 cancer cells but not in human primary hAT2 cells H292 and hAT2 cells were infected with adenovirus at various MOIs for lacZ or HSULF-1 over-expression. Forty eight and 72 hours post-infection, quantitative real-time PCR and Western blot were performed to analyze the expression of HSULF-1 mRNA and protein, respectively. Results showed that the levels of HSULF-1 mRNA and protein were significantly increased (Figure 2, A - C). Seventy-two hours post-infection, phase-contrast microscopy showed that hAT2 cells infected with lacZ adenovirus at $100 \mathrm{MOI}$ (Figure 3A) were morphologically similar to untreated cells (data not shown), and were typically squamous in appearance with a centrally located nucleus. With increasing MOIs $(2-100)$ of HSULF-1 adenovirus, hAT2 cells showed little or no significant change in morphology and density (Figure 3, B - G) compared with those infected with lacZ adenovirus alone. H292 cells infected with lacZ adenovirus were small, polygonal cells with a centrally positioned nucleus (Figure $3 \mathrm{H}$ ) and morphologically similar to untreated cells (data not shown). In contrast to hAT2 cells, the morphology and cell density of H292 cells were altered by HSULF-1 adenovirus in a MOI-dependent manner. Low MOIs [2,5] did not significantly change the morphology or the cell density (Figure 3, I - J), while 10 MOI induced a visible decrease in cell density and an increase in the number of floating cells (Figure 3K). Higher HSULF-1 adenovirus MOIs (20, 50, and 100) not only induced morphologic changes in $\mathrm{H} 292$ cells but also decreased cell density (Figure 3, L - N).

To quantitatively assess the viability of HSULF-1 overexpressing cells compared to lac $Z$ over-expressing control cells, an MTT assay, which measures the activity of mitochondrial enzymes that reduce MTT to formazan and indirectly quantifies viable cells, was performed. In primary human alveolar hAT2 cells transduced with HSULF-1 adenovirus at $100 \mathrm{MOI}$, enzymatic activity was reduced to $90 \%, 83 \%$, and $83 \%$ at 24,48 , and 72 hours, respectively, while hAT2 cells transduced with lacZ adenovirus at $100 \mathrm{MOI}$ showed activity reduced to $92 \%, 87 \%$, and $84 \%$, compared to uninfected controls (Figure 4, A - C).

In H292 cells, 100 MOI of HSULF-1 adenovirus reduced MTT activity to $85 \%, 52 \%$, and $39 \%$ at 24,48 , and 72 hours, respectively, while lac $Z$ adenovirus reduced it to $95 \%, 88 \%$, and $79 \%$ of uninfected controls, respectively. HSULF-1 also significantly reduced MTT activity at 10 to 50 MOIs in H292 cells at 48 and 72

HSULF-1

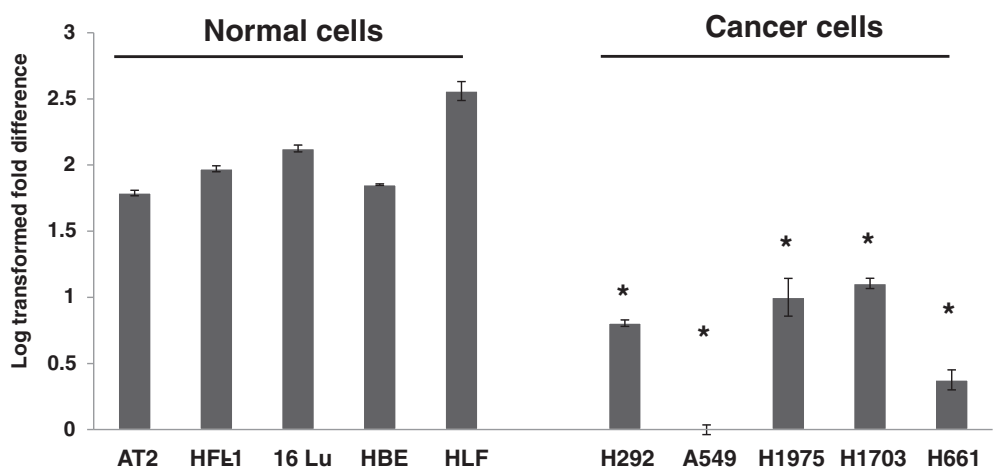

Figure 1 Relative levels of baseline HSULF-1 expression. Five normal cells (HFL-1, 16Lu, hAT2, HBE, and HLF) and five cancer cell lines (A549, H292, H1975, H1703, and H661) were cultured for 48 hours and the levels of HSULF-1 mRNA were analyzed by RT-PCR. Values were normalized to HSULF-1 expression in A549 cells (lowest expression), log transformed to obtain normal distribution, and expressed as means \pm SD from three separate analyses. All the cancer cells express HSulf-1 in a significantly lower level $\left(^{*}\right)$ than all normal cells at a p-value of 0.0004 as determined by one tailed Student's $t$-test. 

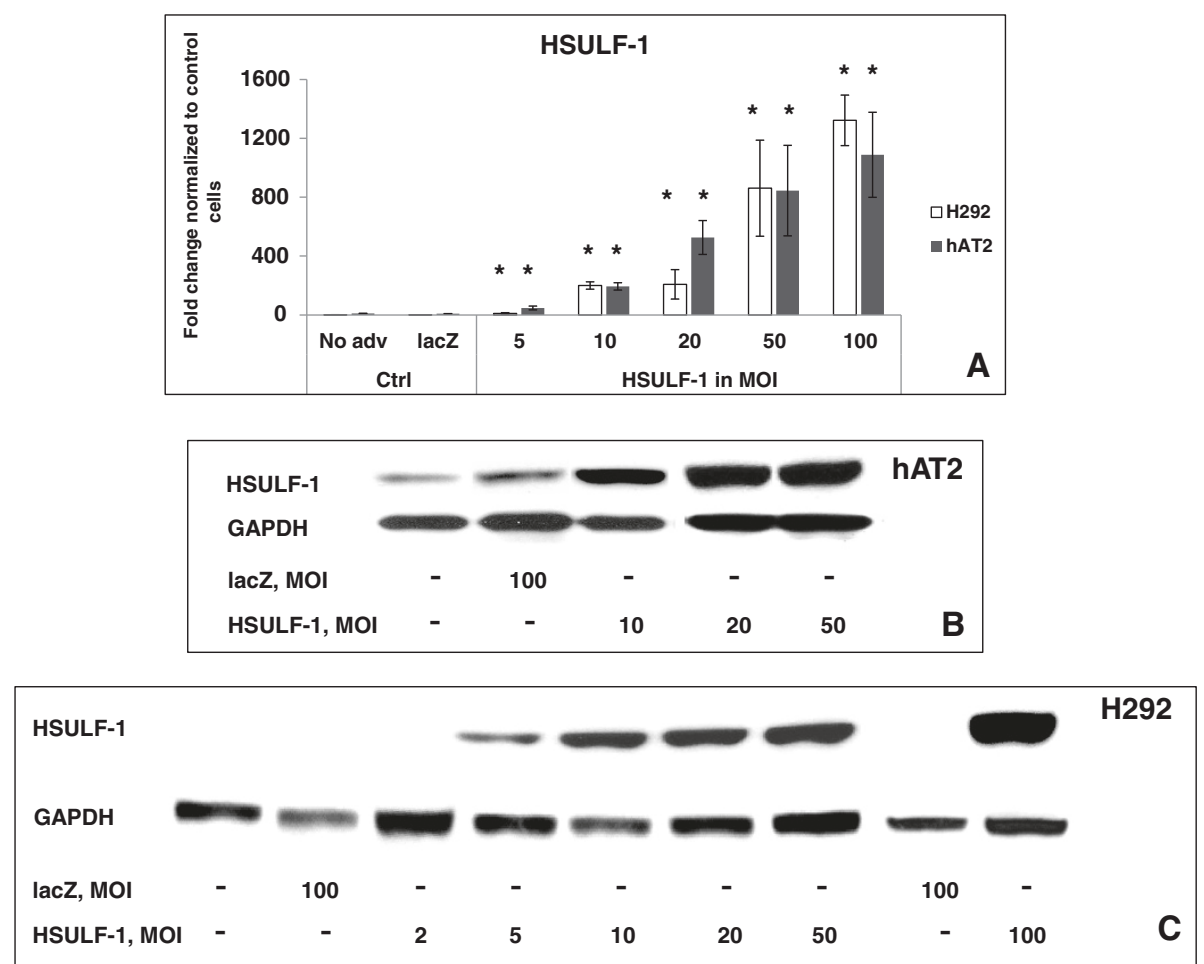

Figure 2 Demonstration of HSULF-1 over-expression in hAT2 and H292 cells by quantitative real time PCR (qRT-PCR) and Western blot. (A) Cells were infected with HSULF-1 adenovirus at MOls from 5 to 100, with lacZ adenovirus at $100 \mathrm{MOl}$ serving as a control. 48 hours post-infection, qRT-PCR was performed to assess the expression level of HSULF-1 mRNA. Values are shown as mean \pm SD from 2 experiments. * Significant differences at $\mathrm{p}<0.05$, compared with untreated and lacZ controls, are determined by Student's $t$-test. Western blot was utilized to assess the expression level of HSULF-1 protein 72 hours post-infection in (B) hAT2 cells and (C) H292 cells.

hours compared to lacZ adenovirus infection (Figure 4, D - F). These results demonstrate that HSULF-1 overexpression lowers formazan conversion activity and thus indicates a reduction in viability in lung cancer cell lines, but not in normal lung cells.

\section{Over-expression of HSULF-1 induces apoptosis and related pathways in lung epithelial cancer cells}

To determine whether the reduced cell viability observed in the MTT assay was caused by apoptosis or by toxicity, lacZ or HSULF-1 over-expressing cells were subjected to TUNEL assay 72 hours after infection to assess DNA fragmentation as a quantitative measure of apoptosis. Results, confirmed in representative photographed fields, indicated that a high level of lacZ adenovirus (100 MOI) did not induce apoptotic cell death in H292 cells, with only rare co-localization of FITC-labeled foci (DNA fragments) with blue (DAPI) stained nuclei (Figure 5A). However, HSULF-1 over-expression did induce an increased number of FITC-labeled foci indicative of apoptosis in $\mathrm{H} 292$ cells, proportional to progressively increasing MOIs (Figure 5, B - G). Ratios of FITC-labeled foci to DAPI-labeled nuclei (total) indicated that HSULF-1 transduction, even at $5 \mathrm{MOI}$, induced significant apoptosis compared to lacZ control at $100 \mathrm{MOI}$, and higher MOIs of HSULF-1 adenovirus resulted in significantly greater apoptosis (Figure $5 \mathrm{H}$ ).

PCR arrays were then used to determine whether apoptotic signaling pathways were altered by HSULF-1 over-expression. Scatter plot analysis illustrated that data points representing activation of these apoptosis-related genes deviated less from those of lac $Z$ adenovirus control in hAT2 cells (Figure 6A) than in H292 or A549 cells (Figures $6 \mathrm{~B}$ and $6 \mathrm{C}$ ) after over-expression of HSULF-1. Genes that were up- or down-regulated more than 2 -fold (Table 1 ) revealed that in hAT2 cells, a total of six genes (BCL2A1, BCL2L11, CASP7, DAPK1, IGF1R, and TNFRSF9) were specifically activated by forced expression of HSULF-1. Of the four pro-apoptotic genes (DAPK1, BCL2L11, CASP7, and TNFRSF9), only DAPK1 was down-regulated $(-4.2$-fold). The other three were up-regulated, but fold changes for two of these were close to 2. TNFRSF9 was up-regulated (4.5-fold). The two anti-apoptotic genes (BCL2A1 and IGF1R) were both down-regulated, but again close to the 2-fold change cutoff. This suggested that, on balance, there was insufficient activation of relevant pro-apoptotic pathways to support apoptosis compared to control cells. 

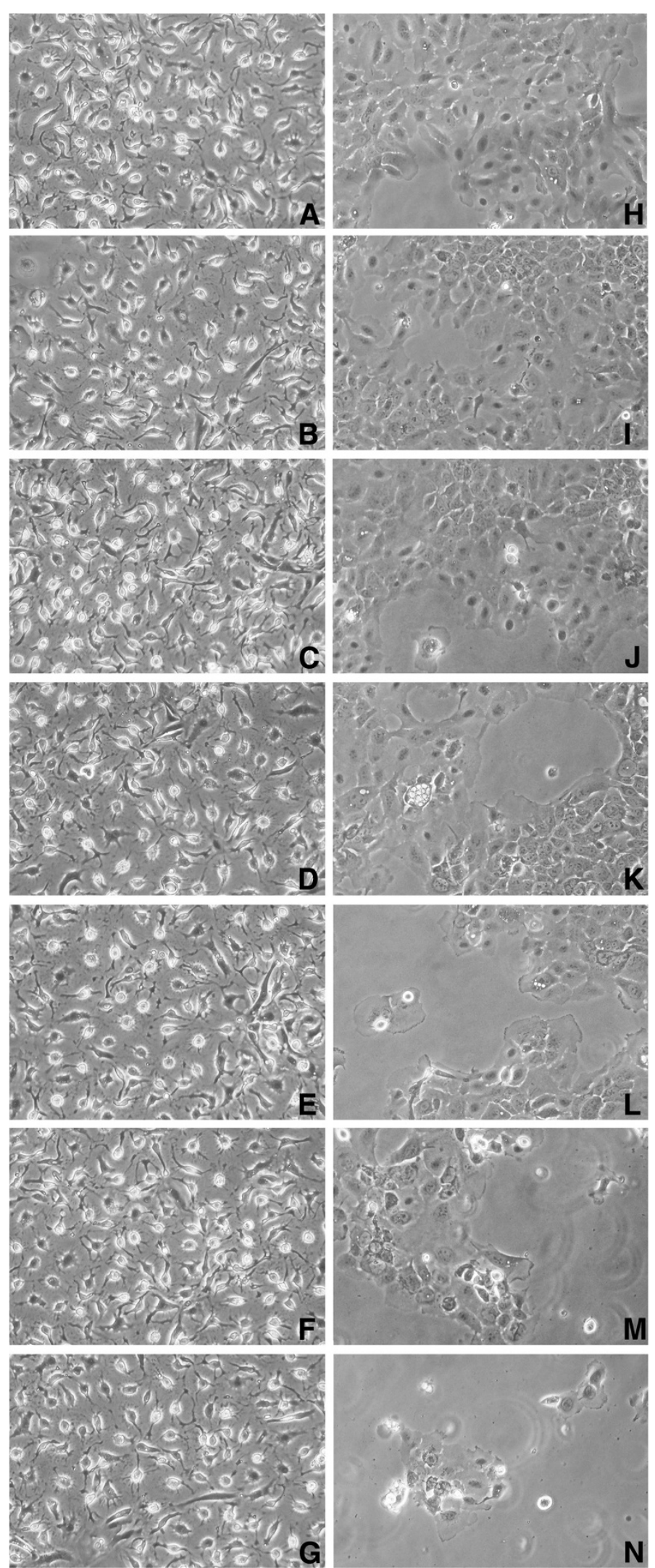

Figure 3 (See legend on next page.) 
(See figure on previous page.)

Figure 3 Representative photomicrographs of hAT2 and H292 cells after over-expression of HSULF-1. hAT2 (B - G) and H292 (I - N) cells were infected with HSULF-1 adenovirus with MOls at 2, 5, 10, 20, 50, and 100 (top to bottom in sequence), with lacZ adenovirus at $100 \mathrm{MOI}$ serving as control (A and $\mathbf{H}$ ). Photomicrographs were taken after 72 hours under a phase contrast microscope at 200X magnification.

In contrast, in $\mathrm{H} 292$ cells, eight pro-apoptotic genes (BAX, CASP6, CASP8, CIDEA, DFFA, FAS, TNFRSF9, and TNFSF10), four anti-apoptotic genes (BAG1, BAG4, $I G F 1 R$, and $B C L 2 A 1)$, and five unrelated genes (GADD45A, CD70, TNFSF8, MCL1, and TP73) were specifically altered by HSULF-1 expression. Of the eight proapoptotic genes, three (CASP6, CASP8, and TNFSF10) were down-regulated, but only CASP6 by a relatively high amount (-4.5-fold). Five pro-apoptotic genes ( $B A X$, CIDEA, DFFA, FAS, and TNFRSF9) were up-regulated, CIDEA (3.1-fold) and TNFRSF9 (7.3-fold) more than the others, which were all close to the cut-off (Table 2). Of the four anti-apoptotic genes, three (BAG1, BAG4, and $I G F 1 R$ ) were slightly down-regulated and only BCL2A1 was up-regulated at a relatively high fold-change (5.3fold). Collectively, the up-regulation of the five proapoptotic genes combined with down-regulation of three anti-apoptotic genes would suggest that, on balance, apoptosis would be favored.

Similarly, in A549 cells, ten pro-apoptotic genes (APAF1, BAX, CASP3, CASP6, RIPK2, TNFRSF10B, TNFRSF25, TNFRSF9, TNFSF10, and LTBR) and three anti-apoptotic genes (BCL2A1, CD4OLG, and XIAP) were specifically altered by HSULF-1 over-expression. Of the ten pro-apoptotic genes, nine (APAF1, BAX, CASP3, CASP6, RIPK2, TNFRSF10B, TNFRSF25, TNFRSF9, and TNFSF10) were up-regulated and only $L T B R$ was downregulated. Of the three anti-apoptotic genes, two (BCL2A1 and $C D 4 O L G$ ) were up-regulated and XIAP was downregulated. Collectively, the up-regulation of nine proapoptotic genes combined with down-regulation of one anti-apoptotic gene would suggest that apoptosis would be favored. This further supported the interpretation that over-expression of HSULF-1 reduced cell numbers through apoptosis in transformed H292 and A549 cells but not in hAT2 normal cells.

\section{Over-expression of HSULF-1 inhibits ERK and Akt signaling in lung cancer cell lines}

It has been shown that HSULF-1 inhibits cell proliferation in several cancers and attenuates the activation of ERK and Akt signaling [8,9,22,23], which is maintained at a constitutively high level. The representative blot in Figure 7 compares activation of two key signal transduction pathway elements, p-ERK and p-Akt, in H292 cells untreated or transduced for lacZ or HSULF-1 overexpression. Western blot analysis indicates that lacZ overexpression slightly increased the levels of phosphorylated ERK and p-Akt, compared with untreated controls.
Over-expression of HSULF-1 reduced the levels of phosphorylated ERK and p-Akt, compared to both the untreated and lacZ over-expression controls (Figure 7A). Densitometric analysis of p-ERK and p-Akt bands normalized against total ERK and Akt, respectively, indicated that over-expression of HSULF-1 significantly inhibited the phosphorylation of ERK (1\%) and Akt $(-38 \%)$ compared with untreated controls, and this inhibition was even more significant compared with lacZ controls (Figure 7, B - C).

To determine whether the signaling inhibition induced by HSULF-1 (i.e., loss of 6-O-sulfate groups) was reversible, a low, biologically relevant dose $(25 \mu \mathrm{g} / \mathrm{ml})$ of heparin, a model HSPG, was added to culture medium for 5 minutes. Heparin alone did not reduce the level of pERK or p-Akt in control cells (non-transduced) nor in lacZ over-expressing cells, but the inhibition of p-ERK and p-Akt with HSULF-1 over-expression was reversed to near control levels (Figure 7A). This was confirmed by densitometric analysis (Figure $7, \mathrm{~B}-\mathrm{C}$ ). These results indicate that the specific removal of 6-O-sulfate groups from extracellular HSPGs by HSULF-1 reduced the high level of constitutive ERK and Akt signaling in NSCLC cells, and this inhibition could be reversed by a brief pulse of sulfated heparin, which presumably counterbalanced the loss of sulfates and thus restored 6-Osulfate-dependent signaling.

\section{Discussion}

HSULF-1 is an important inhibitor of tumor/cancer cell growth [19] and is known to be down-regulated in various cancers, such as ovarian, head and neck squamous carcinoma, breast, gastric, kidney, and hepatocellular cancers [8-10,18,22-24]. One mechanism of HSULF-1 down-regulation is epigenetic silencing of its promoter region by hypermethylation [24]. It follows that downregulation of HSULF-1 would enhance tumor growth, and it has been shown that over-expression of HSULF-1 in tumor cell lines inhibits specific, relevant signaling pathways dependent on growth factors including FGF-2, HB-EGF, HGF, and VEGF $[9,10,13,18,23,25]$. Lai, et al., demonstrated that reduced HSULF-1 expression in ovarian cancers resulted in an increased sulfated environment, which acted to enhance HB-EGF signaling and increase proliferation $[18,20,23,26]$. Another study found that HSULF-1 was down-regulated in several head and neck squamous carcinoma cell lines, and over-expression of HSULF-1 attenuated the activation of ERK/MAPK/ Akt signaling stimulated by FGF-2 and HGF [8]. The 


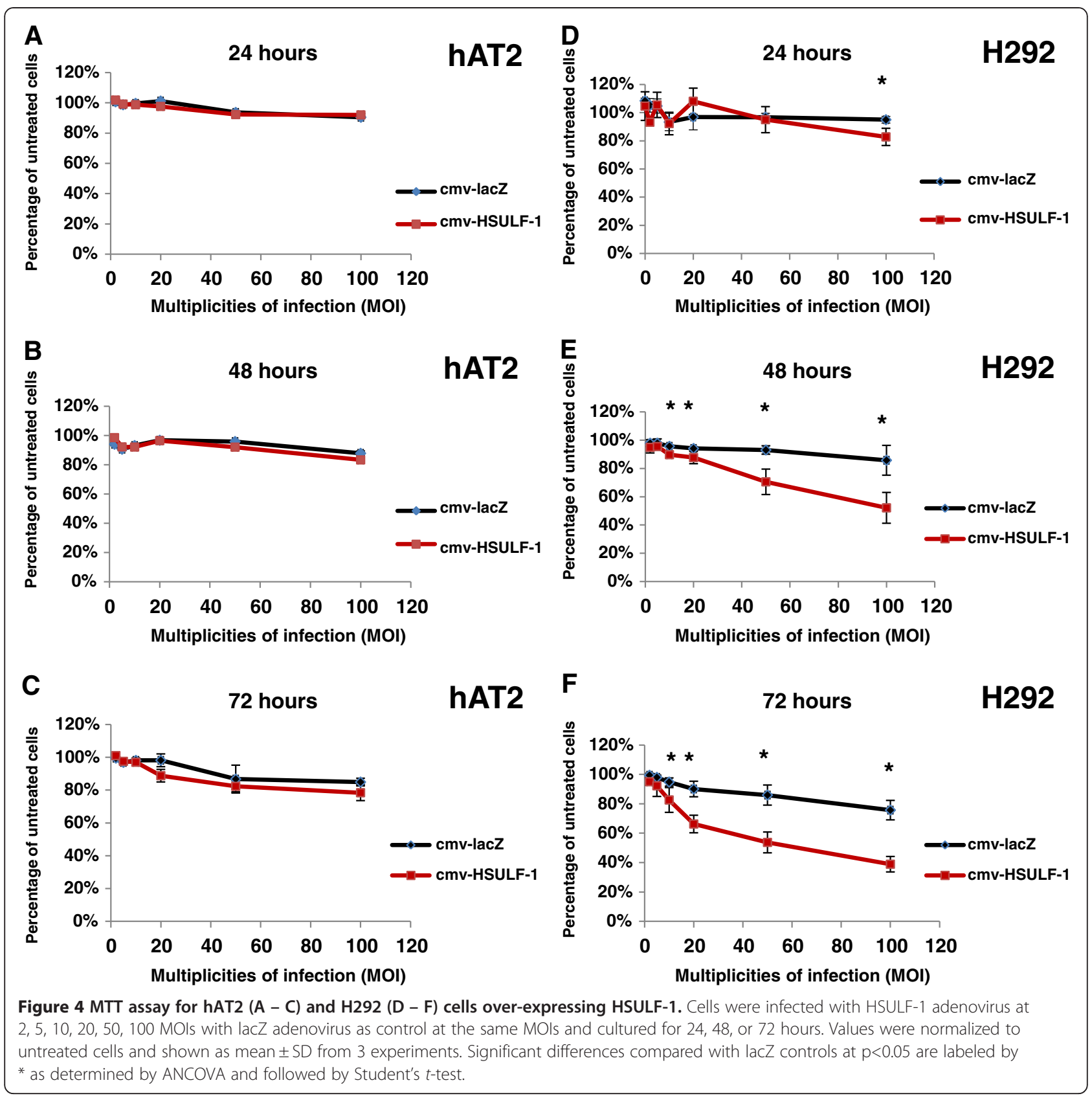

negative regulation by over-expression of HSULF-1 on the FGF-2 signaling pathway is consistent with the fact that 6-O-sulfate groups are requisite for the binding of heparin to FGFR-1, which is necessary for forming a ternary complex with FGF2, and their removal would prevent this interaction [15]. These collective findings support the notion that down-regulating HSULF-1 provides cancer cells an environment sufficient in highly sulfated HSPGs, which act to promote selective growth factor signaling and attendant proliferation.

In this study, the goal was to determine the expression of HSULF-1 in normal and transformed lung cells and its role in regulating cell signaling, survival, and apoptosis in vitro. Although investigated in several cell types recently, the role of HSULF-1 in pulmonary cells remains largely unknown. Results presented here demonstrate that HSULF-1 expression is much lower in lung epithelial cancer cells (A549, H292, H1975, H661, and H1703) than normal cells (hAT2, HFL-1, 16Lu, HBE, and HLF) (Figure 1). This is consistent with previous studies showing that HSULF-1 down-regulation resulted in an environment that promotes proliferation $[10,18,23,26]$.

To study the role of HSULF-1 in tumor growth, we chose to focus on its forced over-expression in H292 

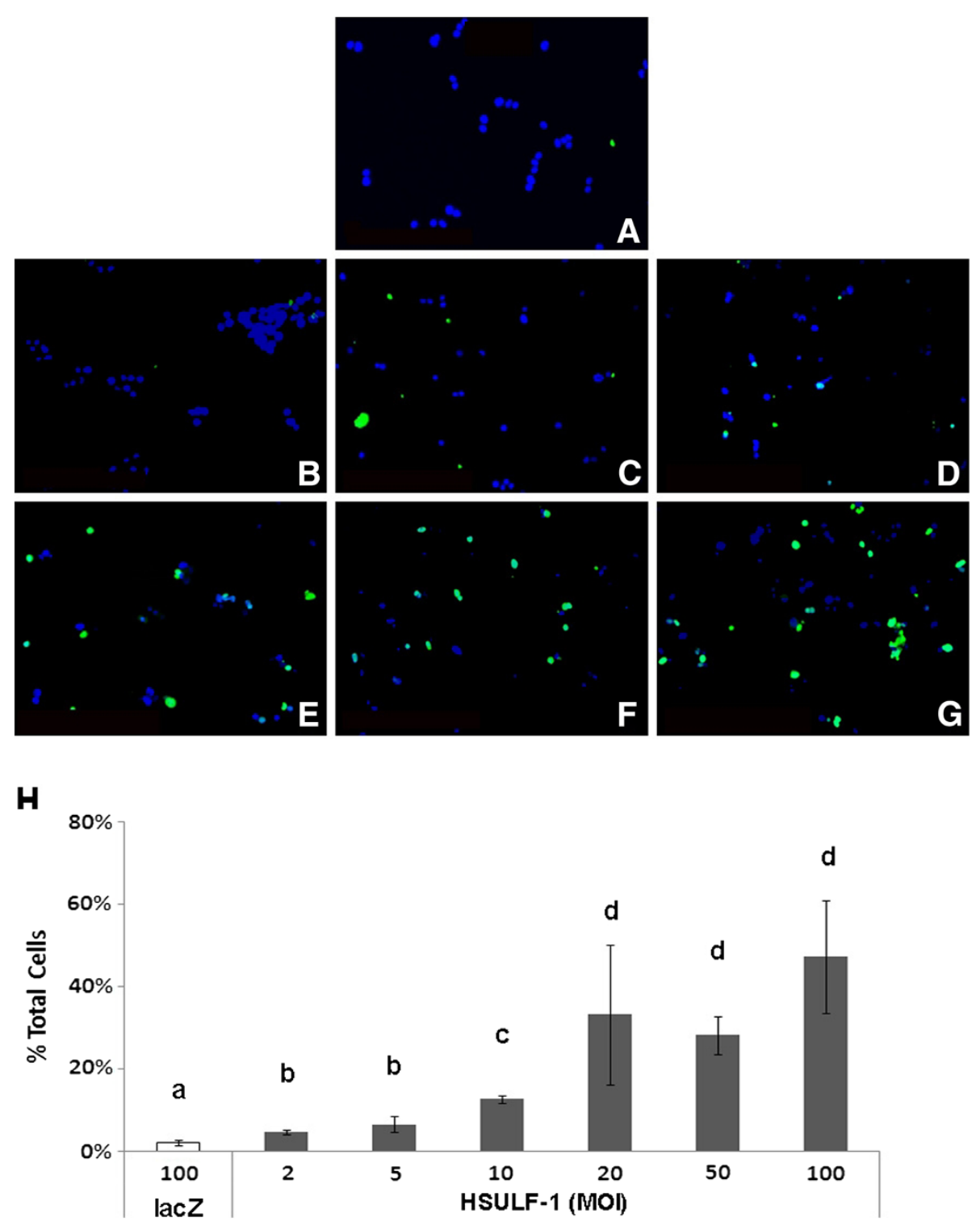

Figure 5 TUNEL assay of $\mathbf{H} 292$ cells over-expressing HSULF-1. Cells were infected with lacZ adenovirus alone (control, A) or HSULF-1 adenovirus at 2, 5, 10, 20, 50, and 100 MOls (sequentially increasing, B - G). Seventy two hours post-infection, TUNEL assay was performed on harvested cells. Photomicrographs were taken of random fields and a minimum of 3 fields from photomicrographs were selected and total cells were counted in each field to achieve a minimum number of 150 total cells. (H) Apoptotic ratios as apoptotic cells/total cells are expressed as Mean \pm SD from different fields. Significant differences between groups at $p<0.05$ as determined by Student's $t$-test are indicated by the letters above each bar, with different letters indicating significant differences between groups.

cells (a lung epithelial cancer cell line) compared with hAT2 cells. Consistent with previous findings, it was found that at 72 hours after adenovirally-mediated overexpression of HSULF-1, cell densities were visibly reduced in $\mathrm{H} 292$ cells in a concentration-dependent manner, but not in normal primary hAT2 cells (Figure 3). This was confirmed by MTT assay, which demonstrated that cell viability in $\mathrm{H} 292$ cells was significantly decreased by over-expression of HSULF-1 while hAT2 cells were unaffected (Figure 4). These results confirmed previous studies in which restored/enhanced expression of
HSULF-1 reduced hepatocellular and breast cancer cell proliferation both in vitro and in vivo $[18,22]$. To further analyze the mechanisms of cell number reduction, TUNEL assay was performed on H292 cells and results showed that apoptosis was induced specifically by HSULF-1 over-expression (Figure 5). This is in agreement with previous studies that showed forced expression of HSULF-1 also increased the apoptosis induced by apicidin (a HDAC inhibitor) in Huh7 and Hep3B hepatocellular cell lines [9]. In addition, PCR array was utilized to analyze apoptosis activation at the gene level. 

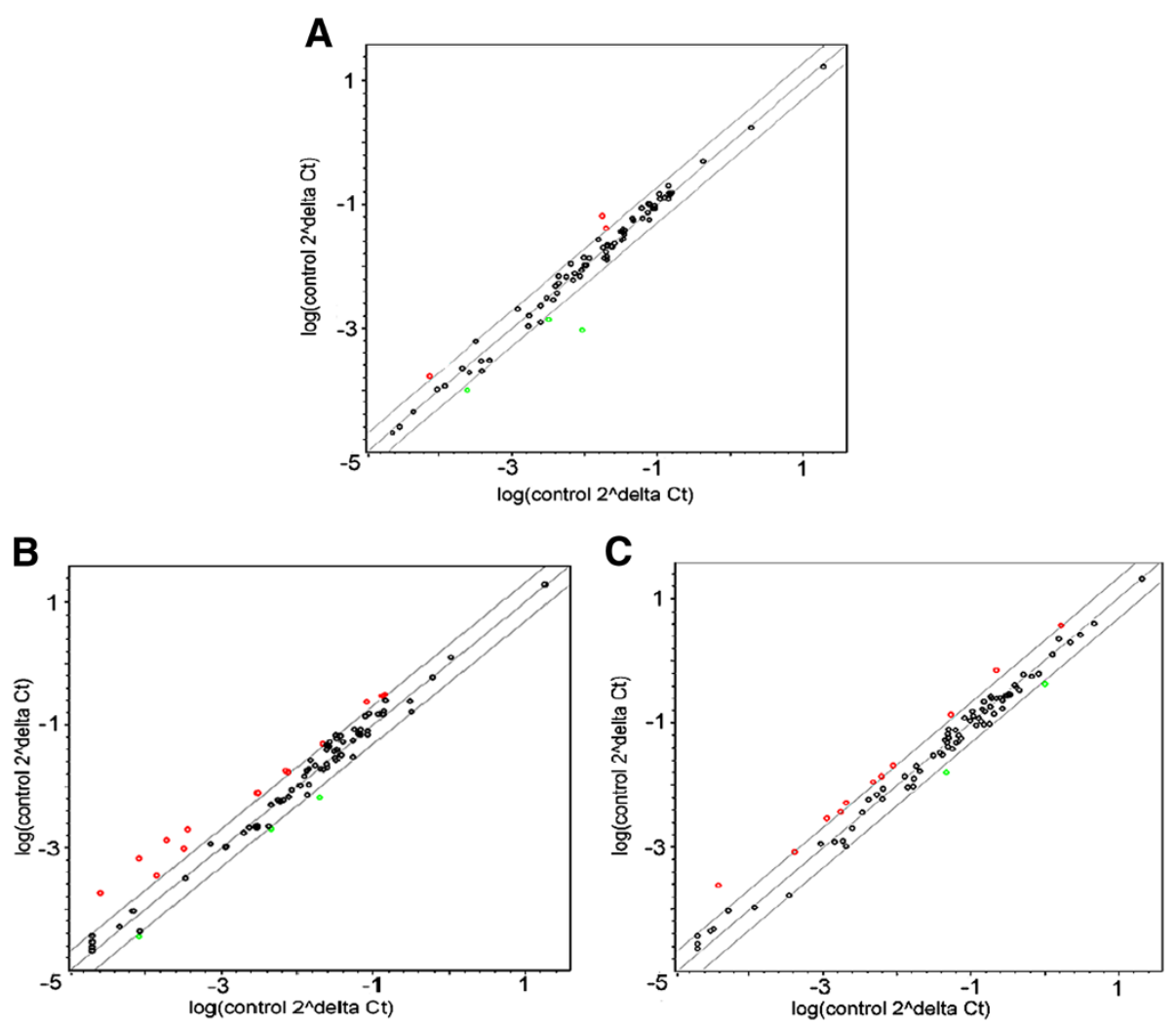

Figure 6 Apoptosis pathway activation in hAT2 (A), H292 (B), and A549 (C) cells over-expressing HSULF-1. At 48 hours post-infection with lacZ or HSULF-1 adenovirus at $10 \mathrm{MOI}$, mRNA was isolated and analyzed with an apoptosis PCR array. Genes significantly up- or down- regulated more than 2 -fold compared to lacZ adenovirus controls are labeled red or green, respectively.

Results showed that in H292 and A549 cells, more genes were activated, and more highly, by HSULF-1 overexpression than in hAT2 cells. Among them, the important cell death pathway effector BAX (induces mitochondrial leakage) was activated in H292 and A549 cells but not in hAT2 cells. Notably, important caspase family genes (CASP3, CASP6, and CASP8) and tumor necrosis family (TNF) genes (TNFRSF10B, TNFRSF25, or TNFSF10) were activated in $\mathrm{H} 292$ or A549 cells but not in hAT2 cells (Tables 1, 2, and 3, Figure 6).
These collective data suggest that normal cells may control their expression of HSULF-1 in order to modulate the surrounding sulfated environment to optimize responses to relevant growth factors. This is in agreement with previous work demonstrating that the optimal interactions of FGF-2 with their low affinity HSPG receptors, or heparin surrogates, lie within a relatively narrow range of concentration [27,28], and that these interactions are sulfate dependent [29]. This paradigm is shifted in cancer cells, wherein their requirements in a

Table 1 Genes that were up- or down-regulated in hAT2 cells by HSULF-1 over-expression

\begin{tabular}{lllc}
\hline AT2 cells & Description & Function & Fold change \\
\hline Gene symbol & $B C L 2$-like 11 (apoptosis facilitator) & Pro-apoptosis & $\mathbf{2 . 1}$ \\
\hline BCL2L11 & Caspase 7 & Pro-apoptosis & $\mathbf{2 . 1}$ \\
\hline CASP7 & Death-associated protein kinase 1 & Pro-apoptosis & $\mathbf{- 4 . 2}$ \\
\hline DAPK1 & TNF receptor superfamily member 9 & Pro-apoptosis & $\mathbf{4 . 5}$ \\
\hline TNFRSF9 & BCL2-related protein A1 & Anti-apoptosis & $\mathbf{- 2}$ \\
\hline BCL2A1 & Insulin-like growth factor 1 receptor & Anti-apoptosis & $\mathbf{- 2 . 3}$ \\
\hline IGF1R & & & \\
\hline
\end{tabular}

hAT2 cells were infected with HSULF-1 adenovirus, total mRNA was isolated, and an Apoptosis PCR array was used to analyze gene expression. Genes that were significantly up- or down- regulated more than 2-fold compared to lacZ adenovirus control are shown. 
Table 2 Genes that were up- or down-regulated in H292 cells by HSULF-1

\begin{tabular}{|c|c|c|c|}
\hline H292 cells & & & \\
\hline$\overline{\text { Gene symbol }}$ & Description & Function & Fold change \\
\hline BAX & $B C L 2$-associated $X$ protein & Pro-apoptosis & 2.1 \\
\hline CASP6 & Caspase 6 & Pro-apoptosis & -4.5 \\
\hline CASP8 & Caspase 8 & Pro-apoptosis & -2.1 \\
\hline CIDEA & Cell death-inducing DFFA-like effector a & Pro-apoptosis & 3.1 \\
\hline DFFA & DNA fragmentation factor & Pro-apoptosis & 2.2 \\
\hline FAS & TNF receptor superfamily member 6 & Pro-apoptosis & 2.3 \\
\hline TNFRSF9 & TNF receptor superfamily member 9 & Pro-apoptosis & 7.3 \\
\hline TNFSF10 & TNF superfamily member 10 & Pro-apoptosis & -2.8 \\
\hline GADD45A & Growth arrest and DNA-damage-inducible, alpha & Anti-proliferation & 2 \\
\hline CD70 & TNF superfamily member 7 & Pro-proliferation & 6.6 \\
\hline TNFSF8 & TNF superfamily member 8 & Pro-proliferation & 5.3 \\
\hline$\overline{M C L 1}$ & Myeloid cell leukemia sequence 1 & Pro/anti-apoptosis & 2.1 \\
\hline TP73 & Tumor protein 73 & Pro/anti-apoptosis & 2.5 \\
\hline$B A G 1$ & BCl-2-associated athanogene 1 & Anti-apoptosis & -2.3 \\
\hline BAG4 & BCl-2-associated athanogene 4 & Anti-apoptosis & -2 \\
\hline$B C L 2 A 1$ & $B C L 2$-related protein $A 1$ & Anti-apoptosis & 5.3 \\
\hline$\overline{I G F 1 R}$ & Insulin-like growth factor 1 receptor & Anti-apoptosis & -2.2 \\
\hline
\end{tabular}

H292 cells were infected with HSULF-1 adenovirus, total mRNA was isolated, and an Apoptosis PCR array was used to analyze gene expression. Genes that were significantly up- or down- regulated more than 2-fold compared to lacZ adenovirus controls are shown.

sulfated environment for maintenance and growth are high, making them very sensitive to reductions in sulfation, as seen with increased HSULF-1.

The impact of alterations in ligand binding events at the cell surface relating to FGF-2, VEGF, and HGF would be expected to be reflected in subsequent signaling pathways and account for the observed biological outcomes. It has been suggested that HSULF-1's hydrolysis of sulfate groups from HSPGs down-regulates the receptor tyrosine kinase activity to attenuate cell growth and survival through signaling pathways regulated by FGF-2, VEGF, and HGF [19,30,31]. Based on these findings, $\mathrm{H} 292$ cells were forced to over-express HSULF-1 and levels of p-ERK and p-Akt, common down-stream targets of signaling pathways triggered by FGF-2, VEGF, and HGF, were analyzed. Results showed that p-ERK and p-Akt were inhibited by HSULF-1, and this inhibition was significantly reversed by restoring sulfated proteoglycans by addition of heparin (Figure 7). This is in agreement with previous studies showing that the loss of response of cells to FGF when lacking endogenous heparan sulfate can be restored by the addition of exogenous heparin [12]. Notably, both basal expression of p-ERK and p-Akt were high in the H292 cells compared with normal hAT2 cells (data not shown), which is typical of cancer cells [32,33] and may account for the heightened sensitivity to HSULF-1-induced reduction in signaling. A plausible mechanism for the apoptosis caused by HSULF-1 over-expression is that the significant reduction in p-ERK and p-Akt is sufficient to block proliferation and promote apoptosis and cell death in $\mathrm{H} 292$ cells, as the anti-tumor drug periplocin does in another NSCLC, A549, through its blockage of ERK and Akt pathways [34].

Interestingly, in contrast to inhibiting ERK and Akt signaling, HSULF-1 has been found to stimulate Wnt signaling and thus increase proliferation in pancreatic cancers [35,36], which reveals that the role of HSULF-1 is somewhat complicated. Recent studies found that HSULF-1 is up-regulated in acute myeloid leukemia, pancreatic adenocarcinomas, $\mathrm{T}$ prolymphocytic leukemia, and in renal carcinoma, compared to corresponding normal tissues [37]. Furthermore, it has been shown that HSULF-1 is expressed at higher levels in lung cancer patient samples compared with normal tissues, and high HSULF-1 expression could be associated with a poor prognosis in lung adenocarcinoma [37].

Several reasons to account for these apparent contradictions have been proposed. First, as shown in our experiments, the expression of HSULF-1 was compared in five lung cancer cell lines and five normal lung cells which were both randomly selected. After log transformation of the RT-PCR data, the results showed that the expression of HSULF-1 was significantly higher in normal cells than in cancer cells, with a p-value of 0.0004 . This indicates that the wide variation in HSULF-1 expression and its effects may be explained in part by the differences between specific cancers and related cell lines 


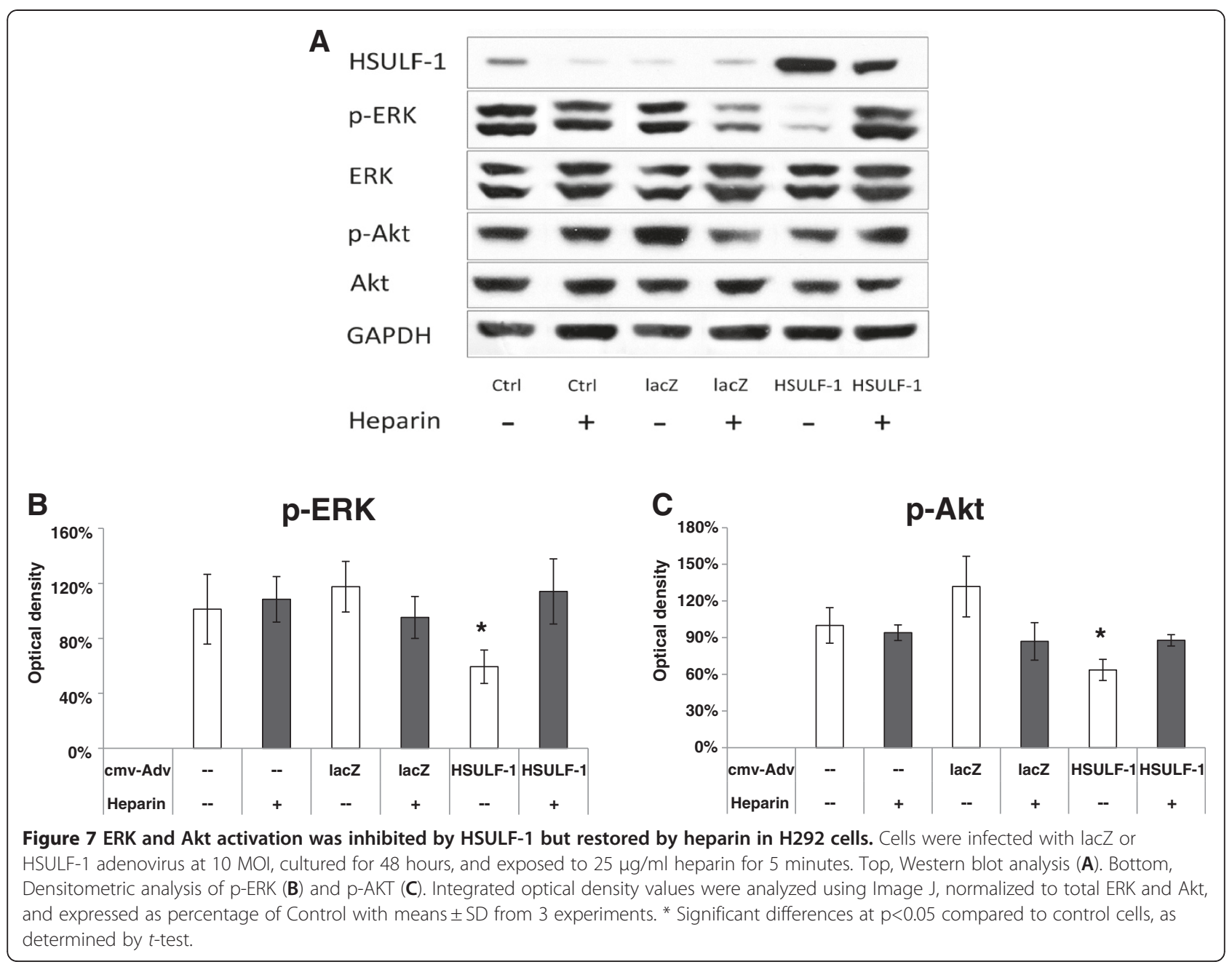

Table 3 Genes that were up- or down-regulated in A549 cells by HSULF-1

\begin{tabular}{|c|c|c|c|}
\hline A549 cells & & & \\
\hline Gene symbol & Description & Function & Fold change \\
\hline APAF1 & Apoptotic peptidase activation factor 1 & Pro-apoptosis & 2.1 \\
\hline BAX & $B C L 2$-associated $X$ protein & Pro-apoptosis & 2.1 \\
\hline CASP3 & Caspase 3 & Pro-apoptosis & 2.2 \\
\hline CASP6 & Caspase 6 & Pro-apoptosis & 2.1 \\
\hline RIPK2 & Receptor-interacting serine/threonine-protein kinase2 & Pro-apoptosis & 5.8 \\
\hline TNFRSF1OB & TNF receptor superfamily member $10 \mathrm{~B}$ & Pro-apoptosis & 2.5 \\
\hline TNFRSF25 & TNF receptor superfamily member 25 & Pro-apoptosis & 2.4 \\
\hline TNFRSF9 & TNF receptor superfamily member 9 & Pro-apoptosis & 2.3 \\
\hline TNFSF10 & TNF superfamily member 10 & Pro-apoptosis & 2.9 \\
\hline LTBR & lymphotoxin beta receptor & Pro-apoptosis & -2.7 \\
\hline$B C L 2 A 1$ & $B C L 2$-related protein $A 1$ & Anti-apoptosis & 2.4 \\
\hline CD4OLG & CD40 ligand & Anti-apoptosis & 2.0 \\
\hline XIAP & X-linked inhibitor of apoptosis protein & Anti-apoptosis & -2.2 \\
\hline
\end{tabular}

A549 cells were infected with HSULF-1 adenovirus, total mRNA was isolated, and an Apoptosis PCR array was used to analyze gene expression. Genes that were significantly up- or down- regulated more than 2-fold compared to lacZ adenovirus controls are shown. 
and genetic variances in patient tissues. Second, in the study by Bret, et al., paired samples were obtained by surgical resection from lung squamous carcinoma and non-malignant neighboring tissues, which should contain different types of cells. Not only the cancer cells but also the cancer stromal cells may secrete HSULF-1, which may play different roles when produced by different cell types [37]. Also, the contributions of surrounding non-cancerous cells and a patient's immune system to the local levels of HSULF-1 in an effort to combat a highly-aggressive cancer cannot be discounted. Thus, the up-regulation of HSULF-1 mentioned in lung squamous carcinoma may be explained partly by the increased expression in surrounding cells. Third, recently-described splice variants of Quail SULF-1 apparently have different functions, as the longer isoform A functions to enhance Wnt signaling while the shorter isoform B inhibits Wnt signaling but promotes angiogenesis [38]. The presence of SULF-1 alternate splicing forms has not yet been confirmed in humans, but it would be logical that a functional isoform could counterbalance or negate the function of the longer HSULF-1 or otherwise contribute to metaplasia in those human cancers over-expressing the isoform. Interestingly, and most recently, HSULF-1 gene polymorphisms were found to correlate with the age of onset, severity, and progression of ovarian cancer in a small study of human patients [39], adding yet another layer of complexity to be explored.

\section{Conclusions}

Collectively, the present study reveals that HSULF-1 is expressed at lower levels in several lung cancer cell lines than in normal cells and its over-expression in H292 cells reduces cell viability and induces apoptosis by inhibiting ERK and Akt signaling. HSULF-1 plays important but complicated roles in cancer progression and inhibition depending on organ/tissue sites, cell types, environment, and those signaling pathways it affects. It should be viewed as an important target of cancer treatment.

\section{Abbreviations}

Akt: Protein kinase B; AT1: Alveolar type 1 cells; AT2: Alveolar type 2 cells; ECM: Extracellular matrix; ERK: Extracellular signal-regulated kinase; FGF-1: Fibroblast growth factor 1; FGF-2: Fibroblast growth factor 2; FGFR: Fibroblast growth factor receptor; HFL-1: Human fetal lung fibroblast; HGF: Hepatocyte growth factor; HSULF-1: Human 6-O endosulfatase 1; HSPG: Heparan sulfate proteoglycan; lacZ: lac operon Z; MTT: 3-(4,5dimethylthiazol-2-yl)-2,5-diphenyltetrazolium bromide; TGF- $\beta$ : Transforming growth factor beta; TUNEL: Terminal deoxynucleotidyl transferase dUTP nick and end labeling; VEGF: Vascular epidermal growth factor.
}

\section{Competing interests}

The authors declare that they have no competing interests.

\section{Authors' contributions}

$\mathrm{HZ}$ performed the experiments, collected and interpreted the data, and wrote the manuscript. DN prepared the adenoviruses and hAT2 cells, helped with protocols, and critically read the manuscript. PS planned the concept and design of the study and read and corrected the manuscript. All authors read and approved the final manuscript.

\section{Acknowledgements}

This study was supported by PHS grants HL44497, HL95411 and the State of North Carolina. We thank Dr. Kenneth Adler, Dr. James Bonner, and Dr. Robert Smart for providing valuable technical and scientific advice.

Supported by PHS grants HL44497 (PLS) and HL95411 (PLS) and the State of North Carolina.

\section{Author details}

'Department of Molecular Biomedical Sciences, Center for Comparative Molecular Translational Research, College of Veterinary Medicine, North Carolina State University, Raleigh, NC 27606, USA. ${ }^{2}$ Department of Environmental and Molecular Toxicology, College of Agriculture and Life Sciences, North Carolina State University, Raleigh, NC 27606, USA.

Received: 27 January 2012 Accepted: 31 July 2012

Published: 8 August 2012

\section{References}

1. Clayton A, Thomas J, Thomas GJ, Davies M, Steadman R: Cell surface heparan sulfate proteoglycans control the response of renal interstitial fibroblasts to fibroblast growth factor-2. Kidney Int 2001, 59(6):2084-2094.

2. Fujiwara Y, Yamamoto C, Kaji T: Proteoglycans synthesized by cultured bovine aortic smooth muscle cells after exposure to lead, Lead selectively inhibits the synthesis of versican, a large chondroitin sulfate proteoglycan. Toxicology 2000, 154(1-3):9-19.

3. Iozzo RV: Heparan sulfate proteoglycans, Intricate molecules with intriguing functions. J Clin Invest 2001, 108(2):165-167.

4. Iozzo RV: Matrix proteoglycans, From molecular design to cellular function. Annu Rev Biochem 1998, 67:609-652.

5. Selva EM, Perrimon N: Role of heparan sulfate proteoglycans in cell signaling and cancer. Adv Cancer Res 2001, 83:67-80.

6. Ai X, Do AT, Lozynska O, Kusche-Gullberg M, Lindahl U, Emerson CP Jr: QSulf1 remodels the 6-O sulfation states of cell surface heparan sulfate proteoglycans to promote wnt signaling. J Cell Biol 2003, 162(2):341-351. PMCID, PMC2172803.

7. Guimond S, Maccarana M, Olwin BB, Lindahl U, Rapraeger AC: Activating and inhibitory heparin sequences for FGF-2 (basic FGF). distinct requirements for FGF-1, FGF-2, and FGF-4. J Biol Chem 1993, 268(32):23906-23914.

8. Lai JP, Chien J, Strome SE, Staub J, Montoya DP, Greene EL, Smith DI, Roberts LR, Shridhar V: HSULF-1 modulates HGF-mediated tumor cell invasion and signaling in head and neck squamous carcinoma. Oncogene 2004, 23(7):1439-1447.

9. Lai JP, Chien JR, Moser DR, Staub JK, Aderca I, Montoya DP, Matthews TA, Nagorney DM, Cunningham JM, Smith DI, Greene EL, Shridhar V, Roberts LR: HSULF1 sulfatase promotes apoptosis of hepatocellular cancer cells by decreasing heparin-binding growth factor signaling. Gastroenterology 2004, 126(1):231-248.

10. Narita K, Staub J, Chien J, Meyer K, Bauer M, Friedl A, Ramakrishnan S, Shridhar V: HSULF-1 inhibits angiogenesis and tumorigenesis in vivo. Cancer Res 2006, 66(12):6025-6032.

11. Kimberley FC, van Bostelen L, Cameron K, Hardenberg G, Marquart JA, Hahne M, Medema JP: The proteoglycan (heparan sulfate proteoglycan) binding domain of APRIL serves as a platform for ligand multimerization and cross-linking. FASEB J 2009, 23(5):1584-1595.

12. Rapraeger AC, Krufka A, Olwin BB: Requirement of heparan sulfate for bFGF-mediated fibroblast growth and myoblast differentiation. Science 1991, 252(5013):1705-1708.

13. Lamanna WC, Frese MA, Balleininger M, Dierks T: Sulf loss influences N2-O-, and 6-O-sulfation of multiple heparan sulfate proteoglycans and modulates fibroblast growth factor signaling. J Biol Chem 2008, 283(41):27724-27735.

14. Pye DA, Vives RR, Hyde P, Gallagher JT: Regulation of FGF-1 mitogenic activity by heparan sulfate oligosaccharides is dependent on specific structural features, Differential requirements for the modulation of FGF-1 and FGF-2. Glycobiology 2000, 10(11):1183-1192.

15. Lundin L, Larsson H, Kreuger J, Kanda S, Lindahl U, Salmivirta M, Claesson-Welsh L: Selectively desulfated heparin inhibits fibroblast 
growth factor-induced mitogenicity and angiogenesis. J Biol Chem 2000, 275(32):24653-24660.

16. Verhagen AP, Ramaekers FC, Aalders TW, Schaafsma HE, Debruyne FM, Schalken JA: Colocalization of basal and luminal cell-type cytokeratins in human prostate cancer. Cancer Res 1992, 52(22):6182-6187.

17. Dhoot GK, Gustafsson MK, Ai X, Sun W, Standiford DM, Emerson CP Jr: Regulation of wnt signaling and embryo patterning by an extracellular sulfatase. Science 2001, 293(5535):1663-1666.

18. Lai J, Chien J, Staub J, Avula R, Greene EL, Matthews TA, Smith DI, Kaufmann SH, Roberts LR, Shridhar V: Loss of HSULF-1 up-regulates heparin-binding growth factor signaling in cancer. J Biol Chem 2003, 278(25):23107-23117.

19. Lai JP, Sandhu DS, Shire AM, Roberts LR: The tumor suppressor function of human sulfatase 1 (SULF1) in carcinogenesis. J Gastrointest Cancer 2008, 39(1-4):149-158. PMCID, PMC2925118.

20. Li J, Mo ML, Chen Z, Yang J, Li QS, Wang DJ, Zhang H, Ye YJ, Xu JP, Li HL, Zhang F, Zhou HM: HSULF-1 inhibits cell proliferation and invasion in human gastric cancer. Cancer Sci 2011, 102(10):1815-21.

21. Dobbs LG: Isolation and culture of alveolar type II cells. Am J Physiol 1990, 258(4 Pt 1):L134-L147.

22. Dai Y, Yang Y, MacLeod V, Yue X, Rapraeger AC, Shriver Z, Venkataraman G, Sasisekharan R, Sanderson RD: HSULF-1 and HSULF-2 are potent inhibitors of myeloma tumor growth in vivo. J Biol Chem 2005, 280(48):40066-40073.

23. Lai JP, Yu C, Moser CD, Aderca I, Han T, Garvey TD, Murphy LM, Garrity-Park MM, Shridhar V, Adjei AA, Roberts LR: SULF1 inhibits tumor growth and potentiates the effects of histone deacetylase inhibitors in hepatocellular carcinoma. Gastroenterology 2006, 130(7):2130-2144.

24. Chen Z, Fan JQ, Li J, Li QS, Yan Z, Jia XK, Liu WD, Wei L, Zhang FZ, Gao H, Xu JP, Dong XM, Dai J, Zhou HM: Promoter hypermethylation correlates with the HSULF-1 silencing in human breast and gastric cancer. Int J Cancer 2009, 124(3):739-744.

25. Presta M, Dell'Era P, Mitola S, Moroni E, Ronca R, Rusnati M: Fibroblast growth factor/fibroblast growth factor receptor system in angiogenesis. Cytokine Growth Factor Rev 2005, 16(2):159-178.

26. Li J, Kleeff J, Abiatari I, Kayed H, Giese NA, Felix K, Giese T, Buchler MW, Friess H: Enhanced levels of HSULF-1 interfere with heparin-binding growth factor signaling in pancreatic cancer. Mol Cancer 2005, 4(1):14. PMCID, PMC1087876.

27. Fannon M, Forsten KE, Nugent MA: Potentiation and inhibition of bFGF binding by heparin, A model for regulation of cellular response. Biochemistry 2000, 39(6):1434-1445.

28. Newman DR, Li CM, Simmons R, Khosla J, Sannes PL: Heparin affects signaling pathways stimulated by fibroblast growth factor- 1 and -2 in type II cells. Am J Physiol Lung Cell Mol Physiol 2004, 287(1):L191-L200.

29. Miao HQ, Ishai-Michaeli R, Atzmon R, Peretz T, Vlodavsky I: Sulfate moieties in the subendothelial extracellular matrix are involved in basic fibroblast growth factor sequestration, dimerization, and stimulation of cell proliferation. J Biol Chem 1996, 271(9):4879-4886.

30. Yue X, Li X, Nguyen HT, Chin DR, Sullivan DE, Lasky JA: Transforming growth factor-beta1 induces heparan sulfate 6-O-endosulfatase 1 expression in vitro and in vivo. J Biol Chem 2008, 283(29):20397-20407. PMCID, PMC2459296.

31. Ji W, Yang J, Wang D, Cao L, Tan W, Qian H, Sun B, Qian Q, Yin Z, Wu M, Su C: HSULF-1 gene exhibits anticancer efficacy through negatively regulating VEGFR-2 signaling in human cancers. PLOS One 2011, 6(8):e23274.

32. Balsara BR, Pei J, Mitsuuchi Y, Page R, Klein-Szanto A, Wang H, Unger M, Testa JR: Frequent activation of AKT in non-small cell lung carcinomas and preneoplastic bronchial lesions. Carcinogenesis 2004, 25(11):2053-2059.

33. Vicent S, Lopez-Picazo JM, Toledo G, Lozano MD, Torre W, Garcia-Corchon C, Quero C, Soria JC, Martin-Algarra S, Manzano RG, Montuenga LM: ERK1/2 is activated in non-small-cell lung cancer and associated with advanced tumours. Br J Cancer 2004, 90(5):1047-1052. PMCID, PMC2409626.

34. Lu ZJ, Zhou Y, Song Q, Qin Z, Zhang H, Zhou YJ, Gou LT, Yang JL, Luo F: Periplocin inhibits growth of lung cancer in vitro and in vivo by blocking AKT/ERK signaling pathways. Cell Physiol Biochem 2010, 26(4-5):609-618.

35. lacobuzio-Donahue CA, Maitra A, Olsen M, Lowe AW, van Heek NT, Rosty C, Walter K, Sato N, Parker A, Ashfaq R, Jaffee E, Ryu B, Jones J, Eshleman JR, Yeo CJ, Cameron JL, Kern SE, Hruban RH, Brown PO, Goggins M: Exploration of global gene expression patterns in pancreatic adenocarcinoma using cDNA microarrays. Am J Pathol 2003, 162(4):1151-1162

36. Nawroth R, van Zante A, Cervantes S, McManus M, Hebrok M, Rosen SD: Extracellular sulfatases, elements of the wnt signaling pathway, positively regulate growth and tumorigenicity of human pancreatic cancer cells. PLoS One 2007, 2(4):e392. PMCID, PMC1849966.

37. Bret C, Moreaux J, Schved JF, Hose D, Klein B: SULFs in human neoplasia, Implication as progression and prognosis factors. J Transl Med 2011, 9(1):72.

38. Sahota AP, Dhoot GK: A novel SULF1 splice variant inhibits wnt signalling but enhances angiogenesis by opposing SULF1 activity. Exp Cell Res 2009, 315(16):2752-2764.

39. Han CH, Huang YJ, Lu KH, Liu Z, Mills GB, Wei Q, Wang LE: Polymorphisms in the SULF1 gene are associated with early age of onset and survival of ovarian cancer. J Exp Clin Cancer Res 2011, 30:5. PMCID, PMC3025876.

doi:10.1186/1465-9921-13-69

Cite this article as: Zhang et al:: HSULF-1 inhibits ERK and AKT signaling and decreases cell viability in vitro in human lung epithelial cells. Respiratory Research 2012 13:69.

\section{Submit your next manuscript to BioMed Central and take full advantage of:}

- Convenient online submission

- Thorough peer review

- No space constraints or color figure charges

- Immediate publication on acceptance

- Inclusion in PubMed, CAS, Scopus and Google Scholar

- Research which is freely available for redistribution

Submit your manuscript at www.biomedcentral.com/submit
C BioMed Central 